\title{
A new non-invasive in situ underwater DNA sampling method for estimating genetic diversity
}

\author{
Gergely Balázs $^{1}$ (D) Judit Vörös ${ }^{2,3}$ (D) . Brian Lewarne ${ }^{4} \cdot$ Gábor Herczeg $^{1}$ (D)
}

Received: 11 December 2019 / Accepted: 13 May 2020 / Published online: 12 June 2020

(c) The Author(s) 2020

\begin{abstract}
DNA-based methods form the cornerstone of contemporary evolutionary biology and they are highly valued tools in conservation biology. The development of non-invasive sampling methods can be crucial for both gathering sample sizes needed for robust ecological inference and to avoid a negative impact on small and/or endangered populations. Such sampling is particularly challenging in working with aquatic organisms, if the goal is to minimize disturbance and to avoid even temporary removal of individuals from their home range. We developed an in situ underwater method of DNA sampling and preservation that can be applied during diving in less than a minute of animal handling. We applied the method on a Herzegovinian population of olm (Proteus anguinus, Caudata), an endangered aquatic cave-dwelling vertebrate, which makes it an excellent model to test the method under the harshest conditions. We sampled 22 adults during cave-diving and extracted sufficient quantity and quality of DNA from all individuals. We amplified 10 species-specific microsatellite loci, with PCR success varying between 6 and 10 loci (median: 7 loci). Fragment length analyses on 9 loci revealed a single allele at all loci across all individuals. This is in stark contrast to four Croatian populations studied with the same 10 loci previously that showed high within-population genetic variation. Our population and the four Croatian populations were genetically highly divergent. We propose that our method can be widely used to sample endangered aquatic populations, or in projects where the disturbance of individuals must be kept minimal for conservation and scientific purposes.
\end{abstract}

Keywords Amphibian · Cave $\cdot$ Conservation genetics $\cdot$ Genetic variation · Population genetics $\cdot$ Swabbing

Electronic supplementary material The online version of this article (https://doi.org/10.1007/s1068 2-020-10053-1) contains supplementary material, which is available to authorized users.

Gergely Balázs

balazsgrg@caesar.elte.hu

Extended author information available on the last page of the article 


\section{Introduction}

DNA-based methods are common tools in contemporary evolutionary biology and conservation biology. Basically, if characterisation of a population is needed, population genetic parameters are among the first population traits of interest. Thanks to the enormous methodological developments seen in the last decade, DNA samples of small quantity and poor quality can be used to gather genetic information even on the genomic scale (Perry et al. 2010; Helyar et al. 2011, Chiou and Bergey 2018). In many situations, lethal sampling is not possible and even invasive methods including tissue or blood sampling are inappropriate due to ethical (e.g. endangered populations with small population size) or scientific purposes (e.g. disturbance of the sampled individuals would interfere with the scientific interpretation).

Over the last few decades many non-invasive DNA sampling approaches emerged to minimise the impact on studied populations using different DNA sources (Lefort et al. 2019), like molted feather (Presti et al. 2013), feces (Mannise et al. 2018) or mucus (Domingues et al. 2019). The non-invasive method with the lowest level of disturbance is based on environmental DNA (eDNA). Here, samples are taken from the environment (e.g. water, soil, air) instead from individuals. Cutting-edge eDNA approaches allow not only testing for the presence of a given species, but also for an assessment of biodiversity (Cristescu and Hebert 2018; Ruppert et al. 2019). Further, it is possible that eDNA will be widely used for answering population genetic questions (Adams et al. 2019). However, there are still many methodological developments required before eDNA methods will become everyday tools in population genetics. Additionally, the need for individual sampling will remain when collecting other individual traits are necessary (Adams et al. 2019). Therefore, non-invasive individual sampling for DNA with minimal disturbance is an important goal. However, non-invasive sampling of individuals in aquatic habitats is often not straightforward, especially in hard-to-access environments, when even temporary removal of the sampled individuals is unacceptable. A prime example for such environments is the underwater cave habitat, which can only be accessed using diving techniques.

Cave habitats provide excellent models to understand adaptation to certain environmental changes, like lack of light, sporadic food supply, simple communities and negligible environmental variation (Culver and Pipan 2009). Furthermore, cave communities are globally endangered and aquatic cave ecosystems are important bioindicators of anthropogenic habitat disturbance due to their high sensitivity to changes in an otherwise stable environment (Culver and Pipan 2009; Romero 2009; White and Culver 2012). Finally, aquatic cave ecosystems are important sources of potable water and thus, understanding how they function is important for humans (Herman et al. 2011). Despite the large potential of aquatic cave ecosystems in evolutionary biology and their high degree of importance for conservation biology and environmental management, ecological or evolutionary studies using up-to-date methodology are scarce at best, but with a promising rise in the number of recent publications (Trontelj 2018). The presently low number of such studies is most probably a result of the difficulty of accessing the habitats and collecting data with a sample size necessary for robust ecological inference.

The olm (Proteus anguinus Laurenti, 1768, Proteidae, Caudata) is the largest cavedwelling vertebrate in Europe, with a long-standing scientific history (e.g. Zois 1807; Brieglieb 1962, 1963). It is known for its extreme characteristics, such as loss of vision, loss of pigmentation (but see Sket and Arntzen 1994), neotenia, high tolerance for low oxygen levels, extreme longevity (probably over 100 years), extreme starvation resistance 
(more than 10 years) and infrequent reproduction (females' reproductive cycle is over 10 years) (Hervant et al. 2001; Issartel et al. 2009; Speakman and Selman 2011; Voituron et al. 2011). Phylogenetic and population genetic analyses have also been published, however, these studies are based on either a low sample size per population (Sket and Arntzen 1994), or have applied destructive or invasive sampling methods (Gorički and Trontelj 2006, Vörös et al. 2019). Even in the best case, the DNA sampling included the temporary removal of individuals from their habitats with an unknown impact on the populations (Zakšek et al. 2017). The species is considered as vulnerable in the IUCN system (Arntzen et al. 2009) and our knowledge of its ecology and behaviour in its natural habitats is extremely limited (Balázs et al. 2020). Therefore, a non-invasive DNA sampling method, where the sampling method includes minimal disturbance is of high interest. Skin swabbing is a common tool for non-invasive DNA sampling in amphibians (Pichlmüller et al. 2013; Ringler 2018).

In the present paper, we aimed to develop and test a non-invasive skin-swabbing-based DNA sampling method that can be used in situ during diving at the exact point of capture. The goal was to establish a protocol where taking and preserving the DNA can be completed during a short time (less than a few minutes), providing samples of sufficient quantity and quality of DNA for population genetic analyses. Such a method would be highly beneficial, because it could be applied across different aquatic ecosystems, such as underwater caves or endangered coral reefs, and on many taxa with mucus on the skin surface. We used a previously genetically unstudied Herzegovinian $P$. anguinus population to demonstrate the efficacy of this method. Based on the expected results, we also aimed to provide the first population genetic evaluation of this population located near the extreme southern limit of the species' presently known geographical distribution.

\section{Materials and methods}

\section{Field sampling}

Our study population was located in the Vruljak 1 Cave in the Gorica District of Trebinje, Eastern Herzegovina. We have been working in the area for more than 10 years and chose this particular population due to its relatively high $P$. anguinus density and its ease of access. We (always two persons at a time) dived in the cave five times between 07 and 11 May 2016 and captured 22 adult individuals. Because adults in this population are marked (Balázs et al. 2015, 2020), repeated sampling was avoided. One diver caught the animal and the other performed the swabbing, which took less than a minute and typically only 20-30 s (for a video of the process, see Electronic supplement). All animals were released at the exact site of capture.

We used a standard buccal swab kit (Isohelix SK-2S, Cell Projects Ltd., Kent, UK) slightly modified for our purpose (Fig. 1, Electronic supplement). The modification included three steps. As a first step, we fixed the swab to the applicator with a thin silk thread to avoid the swab's detachment underwater. Secondly, we cut halfway through the applicator for easier breaking underwater (needed for the placement of the swab to the vial). Thirdly, we placed a piece of polyethylene foil between the ethanol-filled vial and its big cap (Fig. 1) to keep water contamination and ethanol dilution at the minimum level while opening the big cap underwater for placing the swab into the vial. After swabbing, the cotton swab containing the DNA sample was immediately preserved in the 


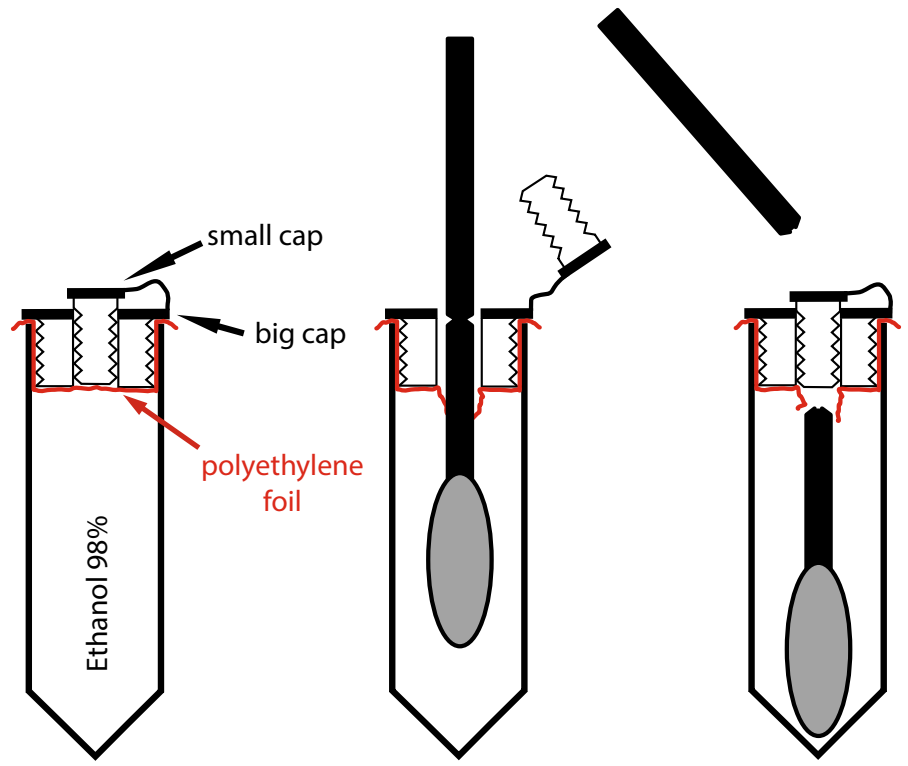

Fig. 1 Schematic drawing of the double-cap vial, the applicator and the steps of sample placement and preservation

ethanol-filled double-capped tubes. In practice, (1) we opened the small cap (Fig. 1) and punctured the polyethylene foil with the swab on the tip of the applicator, (2) we broke the applicator so that the whole sample was within the vial and (3) closed the small cap. Using this technique, water contamination and dilution were minimised.

Because non-invasive DNA sampling methods often yield questionable results due to low quantity of obtained DNA (Taberlet et al. 1999; Broquet et al. 2007; Ficetola et al. 2019), we aimed to validate our method against a sampling technique providing more DNA. Therefore, we collected mucus from one individual by using both our swabbing method detailed above and an interdental brush (Curaprox CPS Prime, Curaden AG, Switzerland). This method can be seen as semi-invasive because of its effect on the sensitive amphibian skin, but it also yields more DNA (see Results), hence, it is useful for controlling for quantity problems with minimal risk on animal health. After returning the samples to the Eötvös Loránd University (Budapest, Hungary), the samples were stored at $-20{ }^{\circ} \mathrm{C}$. In July 2017, the samples were transported to the Laboratory of Molecular Taxonomy (Hungarian Natural History Museum, Budapest, Hungary) and stored at $-80{ }^{\circ} \mathrm{C}$ until the DNA was extracted. The change in storing temperature was a result of the different general lab protocols, holding no methodological relevance.

\section{Laboratory analyses}

DNA was extracted from the swabs using QIAamp DNA Micro Kit (QIAGEN, Hilden, Germany) following the manufacturer's protocol and additionally using QIAshredder columns (Qiagen, Hilden, Germany) after the Proteinase K digestion step. DNA concentration was measured with a NanoDrop1000 spectrophotometer (Thermo Fisher Scientific, Walthem, USA). Ten species-specific microsatellite loci were individually amplified 
following the laboratory protocol of Vörös et al. (2019). In a previous study on four Croatian $P$. anguinus populations, the number of alleles per these loci ranged from 2 to 14 (Table 1), with expected heterozygosity values in the range of $0-0.505$ (Vörös et al. 2019). Polymerase Chain Reaction (PCR) products were visualised on $1.4 \%$ agarose gel. Fragment length analysis was run on an Applied Biosystem/Hitachi 3130 Genetic Analyzer under the FragmentAnalysis 36_POP7 protocol. Data collection and scoring were performed with the Software Peak Scanner v1.0 (Thermo Fisher Scientific, Walthem, USA).

To ensure our results did not reflect cross contamination with $P$. anguinus DNA present in the environment during the sampling procedure, we tested the ten microsatellite primers using environmental DNA as a template. As a first step in this process, we collected $3 \times 1.5$ litres of cave water from the same locality and transferred them to the laboratory. Environmental samples were collected and processed following the protocol developed by Vörös et al. (2017). The presence of $P$. anguinus DNA was confirmed from each eDNA sample detecting a $64 \mathrm{bp}$ long fragment of the mitochondrial control region (Vörös et al. 2017). The ten microsatellite loci were then tested on these templates including one positive control (DNA extracted from a tissue sample originating from a specimen captured in Markarova Cave, Croatia, amplified with $100 \%$ success in Vörös et al. 2019) and one negative control (using the same set of reagents but instead of a template, we loaded $1 \mu$ of sterile water). PCR reaction, visualization of PCR products, fragment length analysis and data scoring were performed as for the 22 Herzegovinan olm individuals explained above.

\section{Statistical analyses}

Because of the lack of genetic diversity (see Results) within our population, basic population genetic indices could not be calculated. We could however compare our population with four Croatian populations using the dataset already published by Vörös et al. (2019). We calculated pairwise $\mathrm{F}_{\mathrm{ST}}$ (fixation index measuring genetic population divergence) between populations using GENEPOP (Raymond and Rousset 1995). Isolation by distance for the five populations was tested using Mantel's test (Mantel 1967) from the comparison of pairwise $\mathrm{F}_{\mathrm{ST}} /\left(1-\mathrm{F}_{\mathrm{ST}}\right)$ values with the logarithm of pairwise geographic distances using

Table 1 The nine analysed microsatellite loci with previously reported allele ranges and allele size present in our Herzegovinian $P$. anguinus population compared to published data from four Croatian populations

\begin{tabular}{llllll}
\hline Loci & $\begin{array}{l}\text { Allele size range in } \\
\text { Vörös et al. (2019) }\end{array}$ & $\begin{array}{l}\text { Allele size } \\
\text { present } \\
\text { study }\end{array}$ & $\begin{array}{l}\text { PCR success rate/ } \\
\text { locus (\%) present } \\
\text { study }\end{array}$ & $\begin{array}{l}\text { Number of alleles } \\
\text { in Vörös et al. } \\
(2019)\end{array}$ & $\begin{array}{l}\text { Number of alleles } \\
\text { in the present } \\
\text { study }\end{array}$ \\
\hline Pa8 & $200-222$ & 213 & 50 & 6 & 1 \\
Pa10 & $222-234$ & 232 & 95 & 3 & 1 \\
Pa20 & $258-295$ & 279 & 73 & 11 & 1 \\
Pa31 & $288-336$ & 330 & 100 & 9 & 1 \\
Pa48 & $389-448$ & $406^{*}$ & 100 & 5 & 1 \\
Pa52 & $402-444$ & $408^{*}$ & 100 & 14 & 1 \\
Pa68 & $182-188$ & 188 & 100 & 2 & 1 \\
Pa106 & $403-429$ & $393^{*}$ & 82 & 7 & 1 \\
Pa107 & $401-437$ & $413^{*}$ & 86 & 6 & 1 \\
\hline
\end{tabular}

*alleles previously not reported 
the programme ISOLDE in GENEPOP on the Web (Raymond and Rousset 1995). To further assess the genetic structure among the five $P$. anguinus populations, we conducted a Principal Coordinate Analysis ( $\mathrm{PCoA})$ on a genetic distance matrix generated from the covariance matrix as implemented in GenAlEx 6.5 (Peakall and Smouse 2006).

\section{Results}

The DNA concentration of the 22 samples measured by spectrophotometer ranged between 15 and $73 \mathrm{ng} / \mu \mathrm{l}(29.29 \pm 14.82 \mathrm{ng} / \mu \mathrm{l}$, mean $\pm \mathrm{SD})$. Absorbance ratios ranged between 1.69 and $2.12(260 \mathrm{~nm} / 280 \mathrm{~nm})$, and $0.9-2.1(260 \mathrm{~nm} / 230 \mathrm{~nm})$. PCR reactions for the 10 microsatellite loci showed 60-100\% success rate. We could conduct fragment length analysis on nine loci, which were homozygous across all individuals (Table 1). Five of the nine alleles were previously reported for $P$. anguinus, three (Pa48, Pa52, Pa107) were within and one (Pa106) was outside the reported range of alleles (Vörös et al. 2019) (Table 1).

We could not amplify $P$. anguinus microsatellite loci using environmental DNA as template and from the negative PCR controls. We successfully amplified DNA of $P$. anguinus from the positive PCR setup control for each of the ten microsatellite loci. The sampling by buccal swab and interdental brush on the same individual provided $73 \mathrm{ng} / \mu \mathrm{l}$ and $503 \mathrm{ng} / \mu \mathrm{l}$ DNA, respectively. We performed amplification of all loci with the interdental brush sample as well, and these amplifications provided exactly the same alleles in number and size as the buccal swab sample.

We found high levels of genetic structure among the five populations, $\mathrm{F}_{\mathrm{ST}}$ ranging from 0.31 to 0.92 (mean $=0.71$; all $P<0.0001$; Table 2). Pairwise $\mathrm{F}_{\mathrm{ST}}$ values were the highest between the Vruljak 1 Cave population and the four Croatian populations (Table 2). Isolation by distance was not significant (Mantel's test, $P=0.09$ ).

The PCoA of microsatellite variation revealed a marked structure among populations belonging to the different hydrogeographical systems. The variance explained by PC1 and PC2 were $35.83 \%$ and $24.6 \%$, respectively. The plot of the two principal coordinates showed clear separation of all populations except for the Rupećica and Markarova Caves, which were genetically more similar than the other populations (Fig. 2).

\section{Discussion}

Our most salient finding is that non-invasive in situ underwater DNA sampling and preservation with a slightly modified commercially available buccal swab kit was successful under the most challenging environmental conditions. The sampling procedure took less

Table 2 Estimates of pairwise $\mathrm{F}_{\mathrm{ST}}$ based on nine microsatellite loci between our study population (Vruljak) and four Croatian populations. Comparisons including our study population are in bold

\begin{tabular}{lllll}
\hline & Markarova & Pincinova & Vedrine & Rupećica \\
\hline Markarova & 0 & & & \\
Pincinova & 0.67 & 0 & & \\
Vedrine & 0.72 & 0.66 & 0 & \\
Rupećica & 0.31 & 0.67 & 0.73 & 0 \\
Vruljak & 0.82 & 0.82 & 0.92 & 0.83 \\
\hline
\end{tabular}




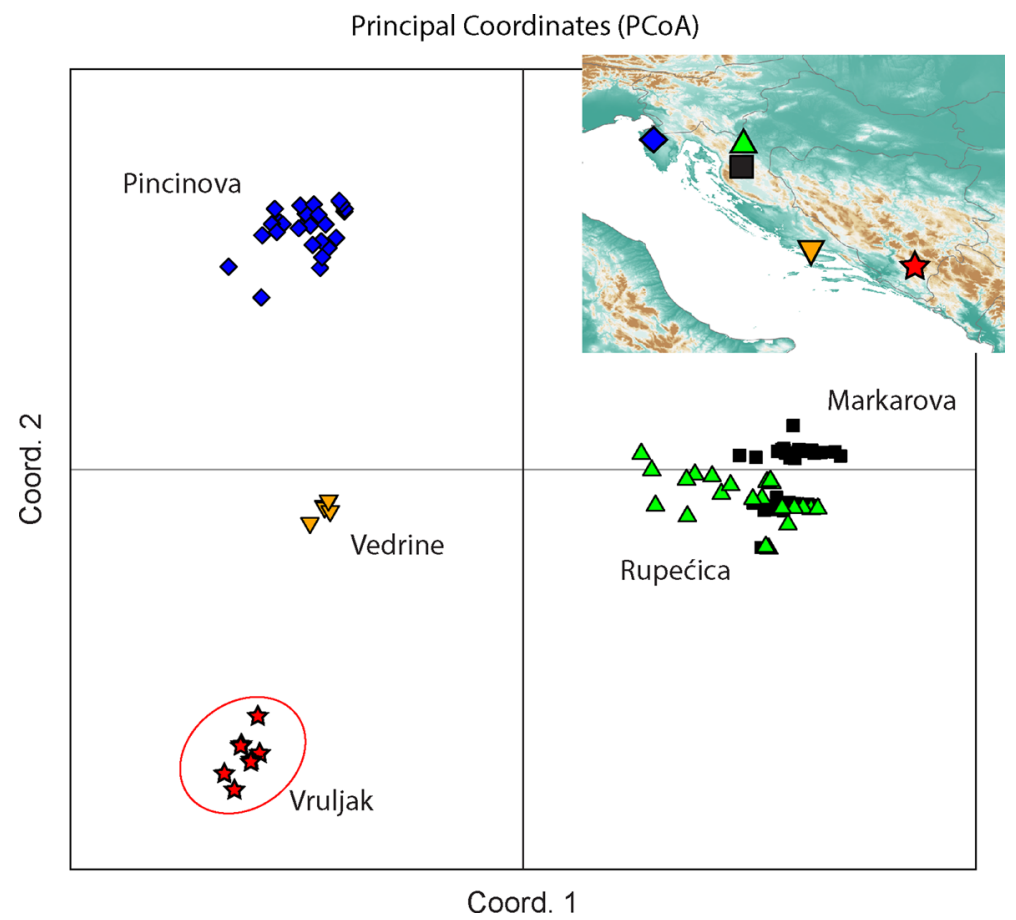

Fig. 2 Genetic structuring among Proteus anguinus individuals from Herzegovina (Vruljak) and Croatia (Pincinova, Vedrine, Rupećica and Markarova Caves) using principal coordinates analysis. Inserted map shows the locations of the five populations

than 1 min for manipulation of the focal animals without having to remove them from their environment. The samples obtained had enough quality and quantity of DNA for analysing nine microsatellite loci. Fragment length analyses showed that our studied $P$. anguinus population exhibits no genetic variation at the studied loci.

DNA analyses are routinely undertaken in a wide array of research fields. However, in certain circumstances, e.g. when the studied habitat, population or individuals are vulnerable, DNA sampling might not be a straightforward process, as killing the animals is often unacceptable for ethical, conservation or scientific reasons (Taberlet et al. 1999, Ficetola et al. 2019). One option is to collect and temporarily remove the animals from their habitat, perform an invasive or preferably non-invasive sampling procedure and then releasing them. This approach can still be problematic as in many cases, we have no data on the short- and long-term fitness effects of the temporary removal, especially when coupled with invasive sampling. For instance, toe-clipping was a widely used method for individually marking amphibians with the presumption that the process was harmless, which proved to be incorrect for at least some species (McCarthy and Parris 2004). Even if focal animals survived this process in perfect health, removal and relocation might affect their future fitness. A number of experimental studies on various taxa showed that temporary removal of adult individuals from their territories can rearrange the social network of the populations, with relocations further complicating the situation (e.g. Thompson 1977; Shutler and Weatherhead 1992; Stiver et al. 2006). The best solution seems to be an in situ, non-invasive sampling approach requiring minimal handling and minimal time. We are 
aware of one published attempt. Kashiwagi et al. (2015) used a toothbrush to collect mucus from Manta rays (Manta birostris) in situ and then preserved the sample on dry land. Later, they successfully used the samples to amplify mtDNA, nuclear DNA and microsatellite loci. Manta rays are special in the sense that they are large (size can be $>5 \mathrm{~m}$ and weight up to 2-3000 kg) and are somewhat docile, so they can be approached and sampled without chase or capture when they are in shallow water and brushed strongly for collecting large amounts of mucus. However, the same approach is not applicable for small-bodied and timid species, where only low quantity of mucus can be collected or in species with more sensitive skin (such as amphibians). Additionally, the sample might become degraded or destroyed in the habitats where reaching dry land takes time, such as in phreatic caves or in large depths. Our approach solves these problems, because the swab does not injure the sensitive skin and - thanks to the immediate sample preservation process-it can work with small sample quantities and long dives. The quantity and quality of our obtained samples were adequate for microsatellite analyses and would most likely be adequate for other approaches, for instance, mtDNA sequencing or SNP-based population structure analyses.

In a previous study, Vörös et al. (2019) found strong genetic differentiation between and significant genetic diversity within four Croatian $P$. anguinus populations using the same species-specific markers as used in the present study. Opposite to this, our population showed zero genetic variation in the studied markers; all nine analysed loci yielded a single allele across the sampled 22 individuals. Four alleles found in our population were absent among the Croatian populations, three of them being within and one slightly below the reported fragment length range (Table 1). Founder effects, genetic bottlenecks, low effective population size and inbreeding could be invoked to explain the zero genetic variation in the Vruljak 1 Cave population. The Vruljak Cave system is considered hydrologically isolated from any other cave ecosystems inhabited by P. anguinus (Lewarne et al. 2010). We have observed a stable high density of adults and plenty of juveniles every year since 2010. According to our capture-mark-recapture data (Balázs et al. 2015, 2020), P. anguinus in this population shows extreme site fidelity, i.e. they typically move a few metres during several years. Lack of gene flow increases the probability of inbreeding (Frankham 2015), while extreme site fidelity coupled with the known extremely long reproductive cycle (on average, 12.5 years, Voituron et al. 2011) might result in a low effective population size. When analysed together with the four Croatian populations, we found that all populations were strongly divergent, our population being the most distant. Isolation by distance was not supported, however, this finding should be considered with caution due to the low number of populations tested. In our study-species, population barriers are not necessarily geographic-distance-dependent and current distribution patterns are shaped by geographic history rather than current dispersion patterns.

Finding effectively zero genetic variation in a natural population is uncommon and could also be a result of several methodological problems. The first is sample size. However, while 22 individuals and nine microsatellite loci are not particularly high numbers, our sample size alone is highly unlikely to cause a massive error (Hale et al. 2012), and Vörös et al. (2019) found significant genetic variation in four Croatian populations with comparable sample sizes, even in a population represented by only six individuals. The second potential problem is particularly relevant for DNA collected by non-invasive methods. When the obtained DNA is low in quantity, allelic dropout, which is the amplification failure of one allele of a heterozygous individual can result in a downward bias in heterozygosity and allelic diversity estimates (e.g. Taberlet et al. 1999; Broquet et al. 2007). However, we found a single allele for every studied locus across all individuals, which is unlikely to be caused by allelic dropout alone, unless genetic variation is already extremely 
low. Further, when comparing two DNA samples of the same individual, one collected by the swabbing method introduced in our paper and the other by applying an interdental brush (yielding seven times more DNA) the results remained the same. Third, there is a possibility that there was a problem with our DNA approach. However, we used speciesspecific primers, protocols already successfully tested on $P$. anguinus, and using negative and positive controls we also tested for environmental DNA in the water. Finally, one should consider biased sampling. We sampled a $270 \mathrm{~m}$ long passage in the Vruljak 1 Cave. The cave is longer than that, and we could not sample $P$. anguinus in small crevices and fissures. However, it is highly unlikely that we ended up sampling a group of individuals without measureable genetic variation within an otherwise variable population.

Taken together, we successfully developed and tested an affordable and reliable method for in situ underwater DNA sampling of small-bodied animals for those species where skinswabbing can be applied. We hope that the method will enable other researchers working with such species to conduct genetic analyses without unnecessarily compromising vulnerable populations and habitats. We note that the method is obviously not cave-specific, but can employed in any aquatic habitats, such as coral reefs, and not only in amphibians, but in fish, molluscs, worms, or any species with mucus on their skin surface. In the studied $P$. anguinus population, we found zero genetic variability in nine microsatellite loci. Although these loci represent only a small portion of the genome, they were found to be highly variable in other populations. This finding was unexpected, because we observed a stable population of a stable number of adults and plenty of juveniles every year during our decade-long monitoring of the cave. The causes and consequences of the lack of genetic variation warrants further studies.

Acknowledgements Open access funding provided byEötvös Loránd University (ELTE). We are highly indebted to Speleološko Društvo "Zelena Brda" (Trebinje, RS-BiH), The Devon Karst Research Society (Plymouth, UK) and the Caudata Hungarian Cave Research Team (Budapest, Hungary) for their indispensable help during fieldwork. The research was funded by the Otto Kinne Foundation and the Hungarian National Research, Development and Innovation Fund for international cooperation (\#SNN-125627). JV was funded by the National Research, Development and Innovation Fund of Hungary NKFIH (KH130360), and the Bolyai János Research Scholarship of the Hungarian Academy of Sciences (BO/00579/14/8). The research was undertaken with approval from the RS-BiH Republic Institute for Cultural-historical and Natural Heritage (RS-BiH Entity Government Official Gazette No. 20/14 The Law on the Protection of Nature, Article 91.) under the authority of a repeat Annual Licence. Before this Authority became Law in 2014, the research was undertaken with general on-going approval of and support from the same Institute. Additionally, the research was undertaken within the remit of "The Proteus Project in Bosnia \& Hercegovina" and its strictly enforced "Prime Directive and Ethical Code of Practice" and its associated "Standards and Guidelines for Working In or Around Hypogean Karst Ecosystems and for Working with Proteus anguinus in its Natural Karst Habitats". The authors declare no conflicts of interest.

Authors Contributions GB and GH developed the sampling method. GB carried out the sampling. BL coordinated the field work. JV coordinated the molecular work. All authors contributed to manuscript writing and revisions.

Open Access This article is licensed under a Creative Commons Attribution 4.0 International License, which permits use, sharing, adaptation, distribution and reproduction in any medium or format, as long as you give appropriate credit to the original author(s) and the source, provide a link to the Creative Commons licence, and indicate if changes were made. The images or other third party material in this article are included in the article's Creative Commons licence, unless indicated otherwise in a credit line to the material. If material is not included in the article's Creative Commons licence and your intended use is not permitted by statutory regulation or exceeds the permitted use, you will need to obtain permission directly from the copyright holder. To view a copy of this licence, visit http://creativecommons.org/licenses/by/4.0/. 


\section{References}

Adams CIM, Knapp M, Gemmell NJ et al (2019) Beyond biodiversity: can environmental DNA (eDNA) cut it as a population genetics tool? Genes 10:192

Arntzen JW, Denoël M, Miaud C et al (2009) Proteus anguinus. The IUCN red list of threatened species 2009: e.T18377A8173419. http://dx.doi.org/10.2305/IUCN.UK.2009.RLTS.T18377A8173419.en. Downloaded on 20 September 2019

Balázs G, Lewarne B, Herczeg G (2015) In situ underwater tagging of aquatic organisms: a test using the cave-dwelling olm, Proteus anguinus. Ann Zool Fenn 52:160-166

Balázs G, Lewarne B, Herczeg G (2020) Extreme site fidelity of the olm (Proteus anguinus) revealed by a long-term capture-mark-recapture study. J Zool. https://doi.org/10.1111/jzo.12760

Briegleb W (1962) Zur Biologie und Ökologie des Grottenolms (Proteus anguinus Laur. 1768). Z Morphol Okol Tiere 51:271-334

Briegleb W (1963) Zur Kenntnis eines Ökotops von Proteus anguinus Laur. 1768. Acta Carsol 3:149-196

Broquet T, Ménard N, Petit E (2007) Noninvasive population genetics: a review of sample source, diet, fragment length and microsatellite motif effects on amplification success and genotyping error rates. Conserv Genet 8:249-260

Chiou KL, Bergey CM (2018) Methylation-based enrichment facilitates low-cost, noninvasive genomic scale sequencing of populations from feces. Sci Rep 8:1975

Cristescu ME, Hebert PDN (2018) Uses and misuses of environmental DNA in biodiversity science and conservation. Ann Rev Ecol Syst 49:209-230

Culver DC, Pipan T (2009) Biology of caves and other subterranean habitats. Oxford University Press, Oxford

Domingues RR, Garrone-NetoD Hilsdorf AWS, Gadig OBF (2019) Use of mucus as a non-invasive sampling method for DNA barcoding of stingrays and skates (batoid elasmobranchs). J Fish Biol 94(3):512-516

Ficetola GF, Manenti R, Taberlet P (2019) Environmental DNA and metabarcoding for the study of amphibians and reptiles: species distribution, the microbiome, and much more. Amphibia-Reptilia 40:129-148

Frankham R (2015) Genetic rescue of small inbred populations: meta-analysis reveals large and consistent benefits of gene flow. Mol Ecol 24:2610-2618

Gorički Š, Trontelj P (2006) Structure and evolution of the mitochondrial control region and flanking sequences in the European cave salamander Proteus anguinus. Gene 378(1):31-41

Hale ML, Burg TM, Steeves TE (2012) Sampling for microsatellite-base population genetic estimates: 25 to 30 individuals per population is enough to accurately estimate allele frequencies. PLoS ONE 7(9):e45170

Helyar SJ, Hemmer-Hansen J, Bekkevold D et al (2011) Application of SNPs for population genetics of nonmodel organisms: new opportunities and challenges. Mol Ecol Resour 11(Suppl 1):123-136

Herman JW, Culver DC, Salzman J (2011) Groundwater ecosystems and the service of water purification. Stanf Environ Law J 20:479-495

Hervant F, Mathieu J, Durand J (2001) Behavioural, physiological and metabolic responses to longterm starvation and refeeding in a blind cave-dwelling (Proteus anguinus) and a surface-dwelling (Euproctus asper) salamander. J Exp Biol 204:269-281

Issartel J, Hervant F, de Fraipont M et al (2009) High anoxia tolerance in the subterranean salamander Proteus anguinus without oxidative stress nor activation of antioxidant defenses during reoxygenation. J Comp Physiol B 179:543-551

Kashiwagi T, Maxwell EA, Marshall AD, Christensen AB (2015) Evaluating manta ray mucus as an alternative DNA source for population genetics study: underwater-sampling, dry-storage and PCR success. Peer J 3:1188. https://doi.org/10.7717/peerj.1188

Lefort MC, Cruickshank RH, Descovich K et al (2019) Blood, sweat and tears: a review of non-invasive DNA sampling. bioRxiv. 385120

Lewarne B, Balázs G, Smith RP (2010) Vol. 1. The Vrelo "Vruljak" (Gorica) Hypogean part-Ecosystem, an interim description and hypogean bio-inventory together with an outline of its current conservation-management problems. -Spelaeobiologica Bosniæ et Hercegovinæ- Monographs in Speleobiology and the Conservation-management of Karst Conduit-aquifer Ecosystems in the Dinaric Karst of Eastern Hercegovina, Bosnia \& Hercegovina (ed B Lewarne). Trebinje

Mannise N, Trovati RG, Duarte JMB, Maldonado JE, González S (2018) Using non-invasive genetic techniques to assist in maned wolf conservation in a remnant fragment of the Brazilian Cerrado. Anim Biodivers Conserv 41(2):315-319 
Mantel N (1967) The detection of disease clustering and ageneralized regression approach. Cancer Res 27:209-220

McCarthy MA, Parris KM (2004) Clarifying the effect of toe clipping on frogs with Bayesian statistics. J Appl Ecol 40:780-786

Peakall R, Smouse PE (2006) GenAlEx 6: genetic analysis in Excel. Population genetic software for teaching and research. Mol Ecol Notes 6:288-295

Perry GH, Marioni JC, Melsted P, Gilad Y (2010) Genomic-scale capture and sequencing of endogenous DNA from feces. Mol Ecol 19:5332-5344

Pichlmüller F, Straub C, Helfer V (2013) Skin swabbing of amphibian larvae yields sufficient DNA for efficient sequencing and reliable microsatellite genotyping. Amphibia-Reptilia 34(4):517-523

Presti FT, Meyer J, Antas PTZ, Guedes NMR, Miyaki CY (2013) Non-invasive genetic sampling for molecular sexing and microsatellite genotyping of hyacinth macaw (Anodorhynchus hyacinthinus). Genet Mol Biol 36(1):129-133

Raymond M, Rousset F (1995) GENEPOP (version 1.2): population genetics software for exact tests and ecumenicism. J Hered 86:248-249

Ringler E (2018) Testing skin swabbing for DNA sampling in dendrobatid frogs. Amphibia-Reptilia 39(2):245-251

Romero A (2009) Cave biology: life in darkness. Cambridge University Press, Cambridge

Ruppert KM, Kline RJ, Rahman MS (2019) Past, present and future perspectives of environmental DNA (eDNA) metabarcoding: a systematic review in methods, monitoring, and application of global eDNA. Global Ecol Conserv 17:e00547

Shutler D, Weatherhead PJ (1992) Surplus territory contenders in male red-winged blackbirds: where are the desperados? Behav Ecol Sociobiol 31:97-106

Sket B, Arntzen JW (1994) A black, non-troglomorphic amphibian from the karst of Slovenia: Proteus anguinus parkelj n. ssp. (Urodela: Proteidae). Contribut Zool 64:33-53

Speakman JR, Selman C (2011) The free-radical damage theory: accumulating evidence against a simple link of oxidative stress to ageing and lifespan. BioEssays 33(4):255-259

Stiver KA, Fitzpatrick J, Desjardins JK, Balshine S (2006) Sex differences in rates of territory joining and inheritance in a cooperatively breeding cichlid fish. Anim Behav 71:449-456

Taberlet P, Waits L, Luikart G (1999) Noninvasive genetic sampling: look before you leap. Trends Ecol Evol 14(8):323-327

Thompson CF (1977) Experimental removal and replacement of territorial male Yellow-breasted chats. Auk 94:107-113

Trontelj P (2018) Structure and genetics of cave populations. In: Moldovan OA, Kováč L, Halse S (eds) Cave Ecology. Springer, Switzerland, pp 269-295

Voituron Y, de Fraipont M, Issartel J, Guillaume O, Clobert J (2011) Extreme lifespan of the human fish (Proteus anguinus): a challenge for ageing mechanisms. Biol Lett 7:105-107

Vörös J, Márton O, Schmidt BR, Gál TJ, Jelić D (2017) Surveying Europe's only cave-dwelling chordate species (Proteus anguinus) using environmental DNA. PLoS ONE 12(1):e0170945. https://doi. org/10.1371/journal.pone.0170945

Vörös J, Ursenbacher S, Jelić D (2019) Population genetic analyses using 10 new polymorphic microsatellite loci confirms genetic subdivision within the Olm, Proteus anguinus. J Hered 110(2):211-218

White WB, Culver DC (2012) Encyclopedia of caves. Academic Press, Chennai

Zakšek V, Konec M, Trontelj P (2017) First microsatellite data on Proteus anguinus reveal weak genetic structure between the caves of Postojna and Planina. Aquat Conserv Mar Freshw Ecosyst 2017:1-6

Zois S (1807) Nachrichten von der im Dorfe Vir bey Sittich vorkommenden Fischart. Laibacher Wochenblatt, July 18,1807

Publisher's Note Springer Nature remains neutral with regard to jurisdictional claims in published maps and institutional affiliations. 


\section{Affiliations}

\section{Gergely Balázs $^{1} \mathbb{D} \cdot$ Judit Vörös ${ }^{2,3}$ (D) Brian Lewarne ${ }^{4} \cdot$ Gábor Herczeg $^{1}$}

1 Behavioural Ecology Group, Department of Systematic Zoology and Ecology, Eötvös Loránd University, Pázmány Péter sétány 1/C, Budapest 1117, Hungary

2 Department of Zoology, Hungarian Natural History Museum, Baross Street 13, Budapest 1088, Hungary

3 Laboratory of Molecular Taxonomy, Hungarian Natural History Museum, Ludovika Square 2-6, Budapest 1083, Hungary

4 The Devon Karst Research Society, Library \& Office, 46, Morley Court, Western Approach, Plymouth, Devon PL1 1SJ, UK 